\title{
Chest Wall Neoplasm
}

National Cancer Institute

\section{Source}

National Cancer Institute. Chest Wall Neoplasm. NCI Thesaurus. Code C4929.

A benign or malignant neoplasm that affects the structures of the chest wall. Representative examples include chest wall lipoma and chest wall lymphoma. 